\title{
Advances in dental veneers: materials, applications, and techniques
}

This article was published in the following Dove Press journal:

Clinical, Cosmetic and Investigational Dentistry

9 February 2012

Number of times this article has been viewed

\author{
Núbia Pavesi Pini' \\ Flávio Henrique Baggio \\ Aguiar' \\ Débora Alves Nunes Leite \\ Lima' \\ José Roberto Lovadino' \\ Raquel Sano Suga Terada ${ }^{2}$ \\ Renata Corrêa Pascotto ${ }^{2}$ \\ 'Area of Restorative Dentistry, \\ Piracicaba Dental School, State \\ University of Campinas - FOP/ \\ Unicamp - Piracicaba, São Paulo, \\ ${ }^{2}$ Area of Restorative Dentistry, \\ State University of Maringá - \\ UEM - Maringá, Paraná, Brazi
}

Correspondence: Renata Corrêa Pascotto State University of Maringá - UEM, Department of Dentistry, Mandacaru Avenue - 1550 - S08, Paraná, Brazil

Tel +55 4430 I I 905 I

$\mathrm{Fax}+554430119052$

Email renatapascotto@gmail.com
Abstract: Laminate veneers are a conservative treatment of unaesthetic anterior teeth. The continued development of dental ceramics offers clinicians many options for creating highly aesthetic and functional porcelain veneers. This evolution of materials, ceramics, and adhesive systems permits improvement of the aesthetic of the smile and the self-esteem of the patient. Clinicians should understand the latest ceramic materials in order to be able to recommend them and their applications and techniques, and to ensure the success of the clinical case. The current literature was reviewed to search for the most important parameters determining the long-term success, correct application, and clinical limitations of porcelain veneers.

Keywords: dental ceramic, porcelain veneers, aesthetic treatment

\section{Introduction}

Restorative aesthetic dentistry should be practiced as conservatively as possible. Currently, the use of adhesive technologies makes it possible to preserve as much tooth structure as is feasible while satisfying the patient's restorative needs and aesthetic desires. With indirect restorations, clinicians should choose a material and technique that allows the most conservative treatment; satisfies the patient's aesthetic, structural, and biologic requirements; and has the mechanical requirements to provide clinical durability. ${ }^{1}$

Based on their strength, longevity, conservative nature, biocompatibility, and aesthetics, veneers have been considered one of the most viable treatment modalities since their introduction in 1983. ${ }^{2}$ Aesthetic veneers in ceramic materials demonstrate excellent clinical performance and, as materials and techniques have evolved, veneers have become one of the most predictable, most aesthetic, and least invasive modalities of treatment. ${ }^{3}$ For this reason, both materials and techniques provide the dentist and patient an opportunity to enhance the patient's smile in a minimally invasive to virtually noninvasive way.

Initially used to treat various kinds of tooth discoloration, porcelain laminate veneers have been increasingly replaced by more conservative therapeutic modalities, such as bleaching and enamel microabrasion. ${ }^{4}$ However, this evolution has not led to a decrease in indications for veneers, as materials and techniques continue to be developed. Ceramic veneers are considered the ultimate option for a conservative aesthetic approach because they leave nearly all of the enamel intact before the veneer is placed. ${ }^{5}$ 
Since its introduction more than two decades ago, ${ }^{6,7}$ etched ceramic veneer restoration has proven to be a durable and aesthetic modality of treatment. The clinical success that the technique has found can be attributed to great attention to detail in a set of procedures, including planning the case, with the correct indication; conservative preparation of the teeth; proper selection of ceramics to use; proper selection of the materials and methods of cementation; and proper planning for the ongoing maintenance of these restorations. ${ }^{6}$ Accordingly, this article discusses the aspects of ceramic laminate veneers restoration that involve materials, applications, and techniques, in order to address some concerns about newer trends, materials, and methods as they relate to the continued success of this modality of treatment.

\section{Methods}

An electronic search of publications from 1991 to 2011 was made using the electronic databases Medline ${ }^{\circledR}$ and PubMed $^{\circledR} .8,9$ The search included only English-language articles published in peer-reviewed dental journals. The keywords were selected listing the following four combinations: (1) "laminate veneer" (2) “ceramic veneer," (3) "porcelain veneer" (4) "dental ceramic." All data from both electronic databases were collected and the duplicates deleted. In general, all selected articles met the well-defined inclusion criteria of being clinical trials, case reports, reviews or systematic reviews, or prospective studies; having a minimum follow-up of 3 years; and written in English.

\section{Review of the literature}

\section{Current materials}

To improve aesthetics in anterior teeth by means of laminate veneers, two types of materials are indicated for their translucency and potential to be used in small thickness: sintered feldspathic porcelain and pressable ceramic, which can also be used milled using a computer-aided manufacturing technique. ${ }^{1,10,11}$ Ceramics can vary from being very translucent to very opaque. In general, the glassier the microstructure (noncrystalline), the more translucent the ceramic will appear; the more crystalline, the more opaque. Other contributory factors to translucency include particle size, particle density, refractive index, and porosity, to name a few. ${ }^{12}$

Porcelain veneers have been a popular means of conservatively restoring unaesthetic anterior teeth since the early 1980s. A number of medium-term clinical studies have confirmed the favorable clinical performance of these restorations, as their maintenance of aesthetics was excellent, patient satisfaction was high, and no adverse effects on gingival health were present. ${ }^{4-7}$ Most authors reported a low failure rate $(0 \%-7 \%) \cdot{ }^{13}$ Higher failure rates $(14 \%-33 \%)$ were noted in other clinical trials, ${ }^{13,14}$ probably due to some predisposing factors, such as unfavorable occlusion and articulation, excessive loss of dental tissue, use of inappropriate luting agents, unprepared teeth, and partial adhesion to large exposed dentin surfaces. Nevertheless, porcelain veneers are considered more durable than direct composite veneers, on the conditions that patients are adequately selected and the veneers are prepared following a meticulous clinical procedure. ${ }^{7,13}$

Della Bona and Kelly ${ }^{15}$ compared the clinical evidence for all-ceramic restorations. They reported that the ceramics are particularly well suited for veneer restorations, which have failure rates (including loss of retention or fracture) of less than $5 \%$ at 5 years. ${ }^{13,15}$ Other authors found that the feldspathic porcelains showed similar long-term survival rates: $96 \%$ in 5 years, $93 \%$ in 10 years, $91 \%$ in 12 years, ${ }^{16}$ and $94 \%$ in 12 years. ${ }^{17}$ Mechanical and biological causes of failures were related to aesthetics $(31 \%)$, mechanical implications (31\%), periodontal support $(12.5 \%)$, loss of retention $(12.5 \%)$, caries $(6 \%)$, and tooth fracture $(6 \%){ }^{18}$ Based on the treatment goal of being as conservative as possible, the first choice will always be these materials. Both feldspathic porcelain and glass-infiltrated ceramics presented long-term survival rates of about $96 \%-98 \%$ in 5 years. ${ }^{15,17}$

Currently, there are systems, like computer-aided design/computer-aided manufacturing (CAD/CAM), that may make the production of veneers easier. $\mathrm{CAD} / \mathrm{CAM}$ restorations have a natural appearance because the ceramic blocks have a translucent quality that emulates enamel and they are available in a wide range of shades. ${ }^{19,20}$ The need for a uniform material quality, reduction in production costs, and standardization of the manufacturing process has encouraged researchers to seek to automate the conventional manual process via the use of this technology since the 1980s. ${ }^{21}$ The chances of success are, therefore, almost as high as those with conventional veneers; $98.8 \%$ of patients describe their $\mathrm{CAD} / \mathrm{CAM}$-produced solution as successful. ${ }^{22}$ Finally, quality is consistent because prefabricated ceramic blocks are free from internal defects and the computer program is designed to produce shapes that will stand up to wear. ${ }^{19}$

Dentists should base their choice of material on the requirements of the tooth being restored, such as the 
indication and the necessity of the tooth preparation to improve aesthetics and function. ${ }^{23}$

\section{Feldspathic veneers}

Porcelain laminate veneers have undergone significant evolution. Nowadays, their use has expanded beyond a simple covering for anterior teeth to include coverage of coronal tooth structures. Feldspathic veneers are created by layering glass-based (silicon dioxide) powder and liquid materials. Silicon dioxide, also referred to as silica or quartz, contains various amounts of alumina. When these aluminum silicates are found naturally and contain various amounts of potassium and sodium, they are referred to as feldspars. Feldspars are primarily composed of silicon oxide $(60 \%-64 \%)$ and aluminum oxide (20\%-23\%), and are typically modified in different ways to create glass that can then be used in dental restorations. ${ }^{12,24,25}$ Thus, porcelain veneer consists of fluorapatite crystals in an aluminum-silicate glass that may be layered on the core to create the final morphology and shade of the restoration. The fluorapatite crystals contribute to the optical properties of the veneering porcelain. Feldspathic porcelain provides great aesthetic value and demonstrates high translucency, just like natural dentition. By using a layering and firing process, ceramists developed veneers that could be made as optically close to natural teeth as possible. ${ }^{25}$

Feldspathic porcelain's mechanical properties are low, with flexural strength usually from 60 to $70 \mathrm{MPa} .{ }^{12}$ Due to the nature of the glass matrix materials and the absence of core material, the veneering porcelains are much more susceptible to fracture under mechanical stress. Therefore, a good bond, in combination with a stiffer tooth substructure (enamel), is essential to reinforce the restoration. ${ }^{1}$ Currently, requests for less-invasive treatments and higher levels of aesthetics have enhanced the indication of feldspathic veneers. With this material, it is possible to have a thickness of less than $0.5 \mathrm{~mm}$, with or without preparation in the enamel. To preserve the health of the gingival tissues and prevent overcontouring, a slight $0.5 \mathrm{~mm}$ reduction of tooth surface is found to work best. When additional wear is necessary on the enamel, it is important to pay attention to the condition of the reminiscent structure, which will affect the bond of the porcelain veneers. The ideal conditions for the bond between the veneer and the substrate are the presence of a rate of $50 \%$ or more of the enamel remaining on the tooth; $50 \%$ or more of the bonded substrate being enamel; and $70 \%$ or more of the margin being in enamel. ${ }^{1,15}$

Feldspathic veneer is manufactured by means of sculpting powder/liquid. The aesthetic value exhibited in these restorations is a result of this technique and, therefore, depends on the ceramist's ability to build depth of anatomy, color, and translucency into the restoration. Because of this, communication between the professional and the ceramist is very important. ${ }^{2}$

\section{Glass-based ceramics}

Glass ceramics may be ideally suited for use as dental restorative materials. Their mechanical and physical properties have generally improved, including increased fracture resistance, improved thermal shock resistance, and resistance to erosion. Improvement in properties depends on the interaction of the crystals and glassy matrix, as well as on the size and amount of crystals. Finer crystals generally produce stronger materials. They may be opaque or translucent, depending on the chemical composition and percent crystallinity. 12,23

Interest in nonmetallic and biocompatible restorative materials increased after the introduction of the feldspathic porcelain crown in 1903 by Land. ${ }^{2}$ Increased strength in glassy ceramics is achieved by adding appropriate fillers that are uniformly dispersed throughout the glass, such as aluminum, magnesium, zirconia, leucite, and lithium disilicate. ${ }^{26}$ For aesthetic veneers, ceramics reinforced by leucite and lithium disilicate are commonly indicated for their optical properties and because they are acid-sensitive. ${ }^{18}$

Filler particles are added to the base glass composition to improve the mechanical properties and optical effects such as opalescence, color, and opacity. ${ }^{27}$ The glass matrix is infiltrated by micron-size crystals of leucite and lithium disilicate, creating a highly filled glass matrix. ${ }^{24}$ The flexural strength depends on the shape and volume of these crystals. This material can be translucent, even with the high crystalline content; this is due to the relatively low refractive index of the crystals. The manufacturer's instructions recommend its use for anterior or posterior crowns, implant crowns, inlays, onlays, and veneers. ${ }^{26}$ Both leucite and lithium disilicate are fabricated through a combination of lost-wax and heat-pressed techniques. ${ }^{20,27}$ The microstructure is similar to that of powder porcelains; however, pressed ceramics are less porous and can have a higher crystalline content because the ingots are manufactured from nonporous glass ingots by applying a heat treatment that transforms some of the glass into crystals. This process can be expected to produce wellcontrolled and homogeneous materials. ${ }^{28}$

The first fillers to be used in dental ceramics contained particles of a crystalline mineral called leucite, added to the ceramic, so that the leucite comprised about $50 \%-55 \%$ of the 
material. This filler was added to create porcelains that could be fired successfully onto metal substructures. Nowadays, it is advantageous for aesthetic veneers because its index of refraction is very close to that of feldspathic glasses - an important match for maintaining some translucency - and because leucite etches at a much faster rate than the base glass. It is this "selective etching" that creates a myriad of tiny features for resin cements to enter, creating a good micromechanical bond. ${ }^{27}$

The ceramics reinforced by lithium disilicate are true glass ceramics, with the crystal content increased to approximately $70 \%$ and the crystal size refined to improve flexural strength. ${ }^{12,27}$ The material is translucent enough that it can be used for full-contour restorations or for the highest aesthetics and can be veneered with special porcelain. Because of the favorable translucency and variety of shades possible, the material can be used for fully anatomic (monolithic) restorations with subsequent staining characterization or as a core material with subsequent coating with veneering ceramics. ${ }^{12}$

These glass ceramics can be used in clinical situations when flexure risk factors are involved. With this material, the thickness must be more than $0.8 \mathrm{~mm}$, except at marginal areas. They can gradually thin to a margin of approximately $0.3 \mathrm{~mm} .{ }^{1,18}$ Therefore, in situations in which there is more than $0.8 \mathrm{~mm}$ of working space, glass ceramics should be considered due to their increased strength and toughness, as well as the presence of sufficient room to achieve the desired aesthetics. These materials are efficient for bonding in substrate, even if less than $50 \%$ of the remaining enamel remains; however, at the margin, at least $30 \%$ of the enamel must be present. ${ }^{1}$

\section{Applications}

The great progress in bonding capability to both enamel and dentin made with the introduction of multistep total-etch adhesive systems, along with the development of highperformance and more universally applicable small-particle hybrid composite resin, has led to more conservative restorative adhesive techniques for addressing unaesthetic tooth appearance. Composite resin can be used to mask tooth discolorations and/or to correct unaesthetic tooth forms and/or positions. However, such restorations still suffer from limited longevity, because composites remain susceptible to discoloration, wear, and marginal fractures, thereby reducing the aesthetic result in the long-term. In the search for more durable aesthetics, porcelain veneers were proposed to be durable anterior restorations with superior aesthetics.

Laminate veneers should be used as a conservative solution to an aesthetic problem. ${ }^{3}$ The correct indication for their use is the main factor in the clinical success of the application of ceramic materials. The indications for a no-preparation or minimally invasive laminate veneer include teeth that have: discoloration that is resistant to vital bleaching procedures; displeasing shapes or contours and/or lack of size and/or volume, requiring morphologic modifications; diastema closure; minor tooth alignment, restoring localized enamel malformations; fluorosis with enamel mottling; teeth with minor chipping and fractures; and misshapen teeth. ${ }^{3-5}$ The severity and extension of any of these factors must be evaluated because they will determine the treatment goals, which have as much to do with restoring proper function as they do with aesthetics. The use of a more aggressive preparation may be necessary to achieve predictable, functional results. In many of these cases, the use of stacked ceramics would often not be the first choice. This factor is important when choosing ceramic material. More extensive restorations would benefit from the stronger leucite-reinforced or lithium disilicate materials, excluding the application of the feldspathic veneer. ${ }^{3}$ The contraindications must be recognized as well. The placement of veneers is contraindicated when there is reduced interocclusal distance; deep vertical overlap anteriorly, without horizontal overlap; or severe bruxism or parafunctional activity. ${ }^{20}$ Severely malpositioned teeth, the presence of soft tissue disease, and teeth with extensive existing restorations are other factors that prevent the placement of laminate veneers. ${ }^{3}$

Generally, feldspathic porcelain materials are indicated for anterior teeth when significant enamel is remaining. When deciding whether to use feldspathic veneers, it is also necessary to undertake a flexural risk assessment. Flexural risk tends to be higher when bonding to a higher extension of dentin, because dentin tends to be more flexible than enamel. If bonding to enamel, the flexural risk is low to moderate. Tensile and shear stress risk assessments are also necessary when deciding on feldspathic porcelain veneers. Generally, higher tensile and shear stresses occur when there are large areas of unsupported porcelain, deep overbites, or overlaps of teeth; when bonding to more flexible substrates, such as dentin and composite; when bruxism is present; and when the restorations are placed more distally. ${ }^{2}$ In these higher-risk clinical situations, the glass ceramics should be considered. Their required major thickness for the restoration 
may compensate for this problem, since increased thickness results in the increasing of strength of this material. ${ }^{18}$

\section{Techniques}

\section{Preparation of teeth}

The preparation of the teeth greatly influences the durability and color (translucency and tonality) of the ceramic restoration, since the tooth preparation will determine the inner superficial contour and the thickness of the ceramic material. This stage is determined by the evaluation of the condition of the teeth, the indications of the clinical situation, and the material chosen (feldspathic or glass ceramic). ${ }^{15,18}$ Concepts regarding the preparation of teeth for porcelain veneers have changed over the past few years. Although early concepts suggested minimal or no tooth preparation, current belief supports removal of varying amounts of tooth structure. , $^{4,18,29}$ The preparation design for laminate veneers should simultaneously allow an optimum marginal adaptation of the final restoration and demonstrate utmost respect for the hard tissue morphology. ${ }^{29}$ Enamel reduction is required to improve the bond strength of the resin composite to the tooth surface. In doing so, the aprismatic surface of mature unprepared enamel, which is known to offer only a minor retention capacity, is removed. ${ }^{7,18}$ In addition and when possible, care must be taken to maintain the preparation completely in enamel to realize an optimal bond with the porcelain veneer. Although the results of the newest generation dentin adhesive systems are very promising, the bond strength of porcelain bonded to enamel is still superior when compared with the bond strength of porcelain bonded to dentin. ${ }^{6,7}$ Thus, one of the main objectives of the technique is to maintain the entire contour in intact enamel whenever possible, because the better the adhesion between the veneer and the prepared tooth, the better the stress distribution in the system enamel-composite-ceramic. ${ }^{18}$

The types of preparation differ only at the incisal region of the tooth. At the cervical third, the gingival margin of the veneer must be located at the same level as the gingival crest or lightly subgingival for the anterior teeth. In this region, it is difficult to obtain a preparation with suitable depth while preserving intact enamel; therefore, in this place, the wear must be approximately $0.3 \mathrm{~mm}$. At the medium third, the preparation may achieve $0.5-0.8 \mathrm{~mm} .^{3,18}$ At the incisal third, the preparation may be modified. The options include the "window" preparation, the most conservative and maintain enamel in incisal third, which results in a visible line between enamel, resin, and ceramic; in addition, the remaining structure is more prone to fracture.
The other possibility is the "feather" preparation, which recovers the incisal of the tooth, maintaining its format. The critical points of this technique are the difficulty in positioning the ceramic restoration at the moment of its cementation and in matching the optical properties of the remaining incisal structure. ${ }^{18}$ So, to obtain adequate color properties at the incisal third of the laminate veneers, the preparation needs to allow a thickness of ceramic of 1.5-2.0 mm, and this is possible with the "overlap" preparation. At the proximal region, the preparation must follow the papilla and extend until interproximal contact. ${ }^{18,29}$

\section{Substrate treatment}

The ceramic veneer technique includes the bonding of a thin porcelain laminate to the tooth surface, enamel and/or dentin, using adhesive techniques and a luting composite to change the color, form, and/or position of anterior teeth. The success of the porcelain veneer is greatly determined by the strength and durability of the bond formed between the three different components of the bonded veneer complex: the tooth surface, the porcelain veneer, and the luting composite. ${ }^{7}$ Because of the improvements to adhesive procedures, it is expected that the biomechanical and structural integrity of the enamel-dentin complex could be partially mimicked using porcelain veneers. The success of bonding to teeth relies on suitable preparation and conditioning of the involved surfaces, the ceramics, and the mineralized dental tissues. ${ }^{30,31}$

\section{Tooth surface (enamel and dentin)}

The enamel surface must be conditioned with phosphoric acid (37\%). This procedure increases the surface energy of the structure, which leads to a perfect wetting of the surface with the bond. At this stage, care must be taken to avoid contamination with saliva and breath moisture, which can reduce the surface energy of the enamel. Therefore, isolation with a rubber dam is highly recommended, which lowers stress input during the clinical procedure. ${ }^{32}$ While the etching of enamel with phosphoric acid leads to a "frosty" surface - a sign of a successful procedure, because of its inorganic composition and perfect etchability - the effect of dentin-bonding agents on dentin is difficult to control, due to its different composition of inorganic and organic parts and tubular structure. It is difficult to obtain the correct dryness or wetness of the surface, which is elementary for a successful bond. Different kinds of dentin-bonding agents deal with surface wetness and the obtaining of a hybrid zone 
in various ways. Multiple bonding-agent generations and different concepts also lead to confusion in dental practices. Last but not least, dentin-bonding systems are highly sensitive to technique, especially when perfect moisture control cannot be guaranteed. ${ }^{33}$

In cases of dentin exposition, sealing this structure with a dental bonding agent is suggested immediately after the completion of tooth preparation and before the final impression itself ${ }^{10,31}$ because the newly prepared dentin is ideal for the adhesion. ${ }^{25,33,34}$ This technique, called the "resin-coating technique," consists of interposing a layer of low viscosity resin between the dental substrate and the luting cement. ${ }^{35,36}$ This procedure seems to produce an increase in the union strength and a reduction of crack formation, bacteria infiltrations, and postoperative sensitivity, as it allows for acid conditioning of the enamel while avoiding the conditioning of the dentin and allowing better control of the conditioning of the enamel. ${ }^{30}$ A substantial clinical advantage is that this measure protects the pulpodentinal organ and prevents sensitivity and bacterial leakage during the provisional phase. The use of a conventional adhesive with three steps or autoconditioning with two steps, with polymerization of the adhesive separated from the composite resin, is recommended. . $^{30,33,37}$

\section{Ceramic}

Effective etching of the ceramic surface is considered an essential step for the clinical success of indirect ceramicbonded restorations and direct ceramic repair procedures. Alteration of the surface topography by etching will result in changes in the surface area and in the wetting behavior of the porcelain. This may also change the ceramic surface energy and its adhesive potential to resin. Differences in ceramic composition will also produce unique topographic changes after etching procedures. ${ }^{18,30}$ The enhancement of bonding through modification of the internal porcelain surface is advocated in order to increase the intimacy of the bond; this may be achieved by exposing the porcelain surface to acid or by air abrasion with alumina particles. The aim of pre-cementation surface modification of the porcelain is to increase the surface modification of the surface area available for bonding and to create undercuts that increase the strength of the bond to the resin luting cement. ${ }^{38}$

The treatment of the ceramic surface is different according to its composition. The three varieties mentioned in this review - feldspathic ceramic, leucite, and lithium disilicate-reinforced ceramic - however, are similar in this respect. All of these must be conditioned with hydrofluoric acid and silane. ${ }^{18,30}$ Acid conditioning with hydrofluoric acid is efficient in removing superficial defects and rounding off the remaining flaw tips, thereby reducing stress concentrators and increasing the overall strength. ${ }^{38}$ Clinical studies have indicated that this protocol significantly increases the expected clinical life span of the restoration. ${ }^{10}$ The difference between these systems is the period of acid conditioning with hydrofluoric acid (9.5\%) (Table 1). Silanization of etched porcelain with a bifunctional coupling agent provides a chemical link between the luting resin composite and porcelain. A silane group at one end chemically bonds to the hydrolyzed silicon dioxide at the ceramic surface and a methacrylate group at the other end copolymerizes with the adhesive resin. Single-component systems contain silane in alcohol or acetone and require prior acidification of the ceramic surface with hydrofluoric acid to activate the chemical reaction. With two-component silane solutions, the silane is mixed with an aqueous acid solution to hydrolyze the silane, so that it can react directly with the ceramic surface. ${ }^{7}$

\section{Luting cements}

The clinical success of laminate veneers depends on the cementation of the indirect restorations, among other factors. ${ }^{11}$ Due to the inherent brittle nature of ceramics, adhesive cementation is used to improve fracture resistance by penetrating flaws and irregularities on internal surfaces, minimizing crack propagation, and allowing a more effective stress transfer from the restorative to the supporting tooth structure. ${ }^{39}$ Luting cements are versatile materials that can achieve excellent aesthetic results. They are recommended for cementation of veneers, inlays, onlays, and all-ceramic restorations and fiber posts, for their adhesion capacity with the tooth, as with restorative materials, such as ceramics and composite resin. ${ }^{37}$ The organic matrix of the cements is generally composed of the same composite resin monomers, while the inorganic component (to a

Table I Ceramic composition and surface treatment protocols

\begin{tabular}{ll}
\hline Ceramic & Conditioning \\
\hline Feldspathic & $9.5 \%$ hydrofluoric acid for 2 to \\
& 2.5 min; I min washing; silane \\
& application \\
Leucite-reinforced & $9.5 \%$ hydrofluoric acid for $60 \mathrm{~s} ;$ \\
& 1 min washing; silane application \\
Lithium disilicate-reinforced & $9.5 \%$ hydrofluoric acid for $20 \mathrm{~s} ;$ \\
& I min washing; silane application \\
\hline
\end{tabular}

Note: Adapted with permission from Soares CJ, Soares PV, Pereira JC, Fonseca RB. Surface treatment protocols in the cementation process of ceramic and laboratorycomposite restorations: a literature review. J Esthet Rest Dent. 2005; 17:224-235. () 2005 John Wiley \& Sons, Inc." 
lesser extent, to give the material viscosity and fluidity) is comprised of silanized particles, usually of glass or silica. ${ }^{18}$ The resin cements have good retention and resistance to fracture, but the adhesive cementation technique is sensitive and associated with a high incidence of postoperative sensitivity. ${ }^{36,40,41}$ Luting cements may be classified into two subgroups: (1) cements associated with the use of conventional or self-etching adhesives, and (2) self-adhesive cements, which do not require any prior conditioning of the tooth structure. ${ }^{40}$

The chemical and physical properties of luting cements are important for the clinical success of indirect restorations. Their properties, ideally, must include: capacity to promote a stable union between the restorative material and the tooth surface; resistance to traction and compression; a suitable elasticity modulus; viscosity to allow for the suitable thickness of the cementation line and the complete settlement of the restoration; and biocompatiblity. ${ }^{41}$ These properties are essential for the durability of the restoration, because they are efficient in preventing microleakage, fracture, or displacement of the restoration. ${ }^{42}$ In comparison with traditional cements, such as zinc phosphate and glass ionomer, several studies point to the luting cements as the most suitable in relation to the physical properties necessary for a cementing agent. ${ }^{43}$ In the case of luting cements (traditional or self-adhesive), these properties are variables in relation to several factors, such as the polymerization of the cement, the substrate treatment, dentin and enamel, and the indirect restoration, among others.

For cementation of porcelain veneers, a light-curing luting composite is preferred. ${ }^{7,39}$ A major advantage of light-curing is that it allows for a longer working time compared with dualcure or chemically curing materials. This makes it easier for the dentist to remove excess composite prior to curing and greatly shortens the finishing time required for these restorations. In addition, their color stability is superior compared with the dual-cured or chemically cured systems. ${ }^{39}$ Nevertheless, it is important that there is enough light transmittance throughout the porcelain veneer to polymerize the light-curing luting composite. The porcelain veneer absorbs between $40 \%$ and $50 \%$ of the emitted light. The thickness of the porcelain veneer is the primary factor determining the light transmittance available for polymerization. The color and the opacity of the porcelain would have less influence on the amount of absorbed light. ${ }^{7,40}$ Linden et $\mathrm{al}^{44}$ reported that the opacity of porcelain became more important for facings with a thickness of $0.7 \mathrm{~mm}$ or more. Consequently, the presence of a porcelain veneer increases the setting time of the resin composite used beneath the veneer. ${ }^{7}$ In the case of porcelain with a thickness of more than $0.7 \mathrm{~mm},{ }^{7,44}$ light-cured resin composites do not reach their maximum hardness. A dual-cured luting composite, which contains the initiation systems for both chemically and light-cured composites, is advisable in these situations. With these latter luting agents, a stronger bond can be obtained with the porcelain. Furthermore, higher values of hardness were reported for the dual-cure resin cements than for the light-cured luting composites, because of their higher degree of polymerization. ${ }^{7}$

\section{Summary and conclusion}

Currently, the properties of ceramics indicate that they are materials capable of mimicking human enamel and their mechanical properties are expanding their clinical applications. Therefore, based on this literature review, it is possible to conclude that the clinical success of laminate veneers depends on both the suitable indications of the patient and the correct application of the materials and techniques available for that, in accordance with the necessity and goals of the aesthetic treatment.

\section{Disclosure}

The authors declare no conflicts of interest in this work

\section{References}

1. McLaren EA, Whiteman YY. Ceramics: rationale for material selection. Compend Contin Educ Dent. 2010;31(9):666-668.

2. McLaren EA, LeSage B. Feldspathic veneers: what are their indications? Compend Contin Educ Dent. 2011;32(3):44-49.

3. Radz GM. Minimum thickness anterior porcelain restorations. Dent Clin North Am. 2011;55(2):353-370.

4. Belser UC, Magne P, Magne M. Ceramic laminate veneers: continuous evolution of indications. J Esthet Dent. 1997;9(4):197-207.

5. Strassler HE. Minimally invasive porcelain veneers: indications for a conservative esthetic dentistry treatment modality. Gen Dent. 2007; 55(7):686-694.

6. Calamia JR, Calamia CS. Porcelain laminate veneers: reasons for 25 years of success. Dent Clin N Am. 2007;51:399-417.

7. Peumans B, Van Meerbeek B, Lambrechts P, Vanherle G. Porcelain veneers: a review of the literature. J Dent. 2000;28:163-177.

8. MEDLINE $^{\circledR}$ [database on the Internet]. Bethesda, MD: National Library of Medicine; nd. Available from: http://www.ncbi.nlm.nih. gov/pubmed/. Accessed January 9, 2011.

9. PubMed.gov [database on the Internet]. Bethesda, MD: National Center for Biotechnology Information, US Library of Medicine; nd. Available from: http://www.ncbi.nlm.nih.gov/pubmed/. Accessed January 9, 2011.

10. Donovan T. Factors essential for successful all-ceramic restorations J Am Dent Assoc. 2008;Suppl 139:14S-18S.

11. Soares CJ, Soares PV, Pereira JC, Fonseca RB. Surface treatment protocols in the cementation process of ceramic and laboratory-composite restorations: a literature review. $J$ Esthet Rest Dent. 2005;17: 224-235.

12. Giordano R, McLaren EA. Ceramics overview: classification by microstructure and processing methods. Compend Contin Educ Dent. 2010;31(9):682-684. 
13. Peumans M, De Munck J, Fieuws S, Lambrecht P, Vanherle G, Van Meerbeek V. Prospective ten-year clinical trial of porcelain veneers. J Adhes Dent. 2004;6(1):65-76.

14. Walls AW. The use of adhesively retained all-porcelain veneers during the management of fractured and worn anterior teeth. Part II: clinical results after 5-years follow-up. Br Dent J. 1995;178:337-339.

15. Della Bona A, Kelly JR. The clinical success of all-ceramic restorations. J Am Dent Assoc. 2008;Suppl 139:8S-13S.

16. Layton D, Walton T. An up to 16-year prospective study of 304 porcelain veneers. Int J Prosthodont. 2007;20(4):389-396.

17. Fradeani M, Redemagni M, Corrado M. Porcelain laminate veneers: 6- to 12-year clinical evaluation - a retrospective study. Int J Periodontics Restor Dent. 2005;25(1):9-17.

18. Della Bona A. Bonding to Ceramics: Scientific Evidences for Clinical Dentistry. São Paulo: Artes Médicas; 2009.

19. Davidowitz G, Kotick PG. The use of CAD/CAM in Dentistry. Dent Clin North Am. 2011;55(3):559-570.

20. Seydler B, Schimitter M. Esthetic restoration of maxillary incisors using CAD/CAM chairside technology - a case report. Quintessence Int. 2011;42:533-537.

21. Wittneben JG, Wright RF, Weber HP, Gallucci GO. A systematic review of the clinical performance of $\mathrm{CAD} / \mathrm{CAN}$ single-tooth restorations. Int J Prosthodont. 2009;22:446-471.

22. Wiedhahn K, Kerschbaum T, Fasbinder DF. Clinical long-term results with 617 Cerec veneers: a nine-year report. Int J Comput Dent. 2005;8:233-246.

23. Spear F, Holloway J. Which all-ceramic system is optimal for anterior for anterior esthetics? J Am Dent Assoc. 2008;Suppl 139:19S-24S.

24. Conrad HJ, Seong WL, Pesun IJ. Current ceramic materials and systems with clinical recommendations: a systematic review. J Prosthet Dent. 2007;98(5):389-404.

25. Culp L, McLaren EA. Lithium disilicate: the restorative material of multiple options. Compend Contin Educ Dent. 2010;31(9):716-720, 722, 724-725.

26. Guess PC, Schultheis S, Bonfante EA, Coelho PG, Ferencz J, Silva NRFA. All-ceramic systems: laboratory and clinical performance. Dent Clin North Am. 2011;55(2):333-352.

27. Kelly JR, Benett P. Ceramic materials in dentistry: historical evolution and current practice. Aust Dent Journal. 2011;56 Suppl 1:84-96.

28. Griggs JA. Recent advances in materials for all-ceramic restorations. Dent Clin North Am. 2007;51(3):713-727.

29. Magne P, Douglas WH. Design optimization and evolution of bonded ceramics for the anterior dentition: a finite-element analysis. Quintessence Int. 1999;30(10):661-672.
30. Della Bona A, Anusavice KJ. Microstructure, composition, and etching topography of dental ceramics. Int J Prosthodont. 2002;15(2): 159-167.

31. Magne P, Douglas WH. Porcelain veneers: dentin bonding optimization and biomimetic recovery of the crown. Int J Prosthodont. 1999;12(2): 111-121.

32. Pilathadka S, Vahalová D. Contemporary all-ceramic systems, part-2. Acta Medica. 2007;50(2):105-107.

33. Frankenberger R, Lohbauer U, Schaible RB, Nikolaenko SA, Naumann M. Luting of ceramic inlays in vitro: marginal quality of selfetch and etch and rinse adhesives versus selfetch cements. Dent Mater. 2008;24(2):185-191.

34. Magne P, Woong-Seup S, Cascione D. Immediate dentin sealing supports delayed restoration placement. J Prosthet Dent. 2007;98:166-174.

35. Jayssoiya PR, Pereira PN, Nikaido T, Tagami J. Efficacy of resin coating on bond strengths of resin cement to dentin. J Esthet Restor Dent. 2003;15:105-113.

36. Udo T, Nikaido T, Ikeda M, et al. Enhancement of adhesion between resin coating materials and resin cements. Dent Mat. 2007;26(4):519-525.

37. Arrais CAG, Ruggeberg FA, Waller JL, Goes MF, Giannini M. Effect of curing mode on the polymerization characteristics of dual-cured resin cement systems. J Dent. 2008;36(6):418-426.

38. Addison O, Marquis PM, Fleming GJP. Adhesive luting of all-ceramic restorations - the impact of cementation variables and short-term water storage on the strength of a feldspathic dental ceramic. J Adhes Dent. 2008;10:285-294.

39. Moraes RR, Correr-Sobrinho L, Sinhoreti MA, Puppin-Rontani RM, Ogliari F, Piva E. Light-activation of resin cement trough ceramic: relationship between irradiance intensity and bond strength to dentin. J Biomed Mat Res. 2008;85B:160-165.

40. Radovic I, Monticelli F, Goracc C, Vulicevic ZR, Ferrari M. Self-adhesive resin cements: a literature review. J Adhes Dent. 2008; 10:251-258.

41. Kumboglu O, Lassila LV, User A, Vallittu PK. A study of the physical and chemical properties of four resin composite luting cements. Int J Prosthodont. 2004;17(3):357-363.

42. Li ZC, White SN. Mechanical properties of dental luting cements. J Prosthet Dent. 1999;81:597-609.

43. Rosenstiel SF, Land MF, Crispin BJ. Dental luting agents: a review of the current literature. J Prosthet Dent. 1998;80:280-301.

44. Linden JJ, Swift EJ, Boyer DB, Davis BK. Photo-activation of resin cements through porcelain veneers. J Dental Res. 1991;70:154-157.
Clinical, Cosmetic and Investigational Dentistry

\section{Publish your work in this journal}

Clinical, Cosmetic and Investigational Dentistry is an international, peer-reviewed, open access, online journal focusing on the latest clinical and experimental research in dentistry with specific emphasis on cosmetic interventions. Innovative developments in dental materials, techniques and devices that improve outcomes and patient satisfac-

\section{Dovepress}

tion and preference will be highlighted. The manuscript management system is completely online and includes a very quick and fair peerreview system, which is all easy to use. Visit http://www.dovepress. $\mathrm{com} /$ testimonials.php to read real quotes from published authors. 